\title{
Musculoskeletal reported symptoms among aircraft assembly workers: a multifactorial approach
}

\author{
Fabrício Augusto Menegon ${ }^{\mathrm{a}, 1}$ Frida Marina Fischer ${ }^{\mathrm{b}}$ \\ ${ }^{a}$ Federal University of Itajubá, Itabira campus, MG, Brazil. \\ ${ }^{\mathrm{b}}$ Department of Environmental Health, School of Public Health, University of São Paulo, SP, Brazil.
}

\begin{abstract}
The aim of this study was to evaluate factors associated with reported work-related musculoskeletal symptoms among aircraft assembly workers. Population consisted of 552 (491 men/61 women) workers who performed tasks related to the work of aircraft assembly. Participants completed a comprehensive questionnaire, including socio-demographic information, habits/lifestyles, working conditions, and work organization. Workers also answered the Nordic Musculoskeletal Questionnaire to obtain data on musculoskeletal symptoms. Multivariate logistic regression was performed to analyze factors associated with musculoskeletal reported symptoms. Results showed that body regions with the highest prevalence of reported musculoskeletal symptoms were similar when referred the past twelve months and the past seven days. Significant factors associated with musculoskeletal symptoms included variables related to conflicts at work, sleep problems, mental fatigue, and lack of time for personal care and recovery. Working time in the industry was associated only with reports for the last seven days and regular physical activity off-work seems to be a positive factor in preventing musculoskeletal symptoms for the past twelve months. The results highlight the multi-factorial nature of the problem. Actions to prevent musculoskeletal diseases at the aircraft assembly work should consider multiple interventions that would promote better recovery between work shifts.
\end{abstract}

Keywords: ergonomics, work analysis, shiftwork, health-related problems, work demands

\section{Introduction}

The aircraft assembly process comprises positioning of parts, drilling, reaming, adjustments and driving rivets to build the plane's fuselage structure. Work activity in this production context was characterized as presenting high physical and cognitive demands, mainly because of the technical issues involved in the assembly and the requirement of intense manual work [19].

Work-related musculoskeletal symptoms $[4,6,12]$ and accessibility issues [16] that can trigger these symptoms were former reported for this work activity. In Brazil, a previous study evaluated 117 of aircraft assembly workers about their perception of pain and discomfort at work [19]. The main reported complaints were in the lower back, neck, shoulders, arms and wrists. However, the study did not examine the factors associated with musculoskeletal symptoms.

Factors associated with musculoskeletal symptoms were presented in previous studies for different occupations $[17,18]$ and included variables such as work postures and movements, thermal comfort in the workplace, furniture design for work and recovery time.

It was raised the study hypotheses that individual features, combined with working conditions, including the work organization and living conditions can potentially trigger health outcomes.

The aim of this study was to evaluate factors associated with reported work-related musculoskeletal symptoms among aircraft assembly workers.

\footnotetext{
${ }^{1}$ Corresponding author. Dr. Fabrício Augusto Menegon. UNIFEI, Itabira campus. Rua Hum s/n, Distrito Industrial II, zip code 35903-081 Itabira, MG, Brazil. Tel./Fax: +55 313834 3544. E-mail: fmenegon@unifei.edu.br
} 


\section{Methods}

This study is characterized as a non-experimental descriptive study, with a cross sectional design. It was approved by the Ethics Committee of the School of Public Health, University of São Paulo (Protocol 1746/2008).

The study population consisted of 552 workers (491 men and 61 women) who performed tasks related to the work of aircraft assembly and completion. Data collection was conducted from January 2009 to March 2010.

The workers signed a consent form to participate in the study. All participants were employees of the studied company and worked in the studied sector for at least six months before data collection began. The study included workers of both sexes, regardless of age. Workers who were away from work due to medical reasons or any other reason that prevent them from responding to the questionnaires were excluded from the study. Also, those who were performing work in other sectors, or returned to assembly work less than 6 months were excluded from the study.

Participants worked in three fixed shifts. The production operated continuously from 5:51 a.m. on Monday, starting the $1^{\text {st }}$ shift until 10:32 a.m. on Saturday, and ending with the night shift (table 1). On weekends production was stopped.

Ergonomic work analyses were performed. It was observed the work activities of aircraft assembly during 25 hours, in all shifts. During the observations the researcher accessed documents that helped to understand the tasks, such as production orders, routings of operations, managing spreadsheets and flowcharts of the assembly process.

A description of the production process was carried out. It involved the characterization of tasks, the assembly processes, tools, machinery and personal protective equipment used.
Participants completed a comprehensive questionnaire, including socio-demographic information, habits/lifestyles, working conditions and work organization. Workers also answered the Nordic Musculoskeletal Questionnaire (NMQ) [11] validated to Portuguese spoken in Brazil [13] to obtain data on musculoskeletal symptoms related to work. These symptoms were reported as aches, pain, discomfort and numbness in various body regions.

Associations between the independent and dependent variables (musculoskeletal symptoms) were performed using Pearson's Chi-square test $\left(\chi^{2}\right)$. Variables which presented an association of $p \leq 0.20$ were selected for entry into the multivariate logistic regression modeling. It was used stepwise-forward selection to the inclusion of variables. Odds ratio (OR) crude and adjusted, and confidence intervals (CI 95\%) were obtained for each independent variable in the final model. Significance of the models was obtained by Hosmer-Lemeshow test. The significance level was set at $p<0.05$. The dependent variables were: absence $($ no $=0)$ and presence $($ yes $=1)$ of musculoskeletal symptoms in the last 12 months and absence $($ no $=0)$ and presence $($ yes $=1$ ) of musculoskeletal symptoms in the last 7 days.

\section{Results}

\subsection{Work activity in aircraft assembly}

The aircraft assembly was divided into five main sectors: 1. Forward fuselage structural assembly, 2. Central fuselage structural assembly, 3. Fuselage junction, 4. Structural completion and equipping, and 5. Pre assembly cell. Each sector was responsible for assembling a part of the fuselage.

The junction of all parts of the fuselage (forward, central and rear fuselages) occurred in the fuselage junction sector, forming the fuselage of the aircraft.

Table 1

Daily and weekly working hours according to the shifts of the aircraft assembly sector of a Brazilian aircraft industry, $2009-2010$.

\begin{tabular}{ccccc}
\hline Shifts & Days & Working shifts & Duration daily & Duration weekly \\
\hline 1 & Monday - Friday & $5: 51 \mathrm{am}-3: 36 \mathrm{pm}$ & 8 hours and 45 minutes & 43 hours and 45 minutes \\
2 & Monday - Friday & $3: 36 \mathrm{pm}-1: 34 \mathrm{am}$ & 8 hours and 58 minutes & 44 hours and 50 minutes \\
3 & Monday - Thursday & $8: 41 \mathrm{pm}-6: 30 \mathrm{am}$ & 8 hours and 49 minutes & 44 hours and 33 minutes \\
3 & Friday - Saturday & $0: 15 \mathrm{am}-10: 32 \mathrm{am}$ & 9 hours and 17 minutes & \\
\hline
\end{tabular}

In each sector, there was a production supervisor and one or two monitors who were more experienced workers and assisted the others in resolving assembly problems. The assembly of subsets and smaller parts used later in the structural assembly in all sectors were performed on workbenches. They were smaller pieces that should be pre-assembled to form larger pieces. The assembly of sets and segments and the 
junction of the fuselage were performed on assembly jigs.

Workers were classified into three distinct occupational categories: mechanical assembler of aeronautical structures, mechanical assembler of the aircraft, and electrician aircraft assembler. They were divided into work teams.

The teams were composed of workers with different experience levels. The workers of each team were organized in floor jigs, according to the position of the parts to be assembled and the final piece to be produced.

The organization and division of tasks were resolved between the workers themselves. The floor jigs provided enough rigid and stable structure to offer conditions of fixation and alignment of parts consistent with the compliance requirements of production. The floor jigs and workbenches configured the jobs sites of the aircraft assembly work and influenced the assembly process, the reaching possibilities, body postures adopted and efforts performed by the workers.

The control over the assembly processes in each floor jig was made by a visual management policy so that everyone involved in the production (managers, supervisors and workers) could follow the evolution of the assembly process in any specific stage, as well as to know the times provided for each assembly. Thus, alongside each floor jig, management charts were posted to describe all tasks to be performed in that workplace as well as the time allotted to each task. This time-based management of the work tasks was in conflict with the needs of the workers to adjust their work pace.

The management chart showed exactly how much each shift performed in the assembly work when a particular task was not finished in one shift, but completed in the following one. The nonconformities found during assembly were recorded in the charts and later reported to assistants and supervisors for appropriate referrals.

One of the most significant assembly work features was the collective nature of the work organization. The tasks performed conditioned the organization of workers into work teams. The goals were achieved only through the joint work and the collaboration among workers.

The assembly of the aircrafts began from the receipt of primary parts assembled in other sections of the industry itself or from external assemblers called "partners". Another observed work characteristic was that the earlier the stages of assembly, the best the possibilities workers have to access assembly points in the jigs.

The reported and observed difficulties to perform the tasks were in ascending order. This means that as the product moved through the assembly process, greatest difficulties were experienced by workers in terms of access points to the use of hand tools. These difficulties were outweighed by the adoption of extreme work postures (body movements of great amplitude and awkward postures).

The assembly process also involves joining of different aluminum structures such as plates, frames, stringers, beams, butt-joint splices and coatings through fasteners (rivets). For this purpose, thousands of rivets were used throughout the processes, installed through manual labor.

The work cycles were long and there was a significant diversity of tasks within each cycle. The work cannot be characterized as repetitive, since the activity did not show classic repetitiveness of movements as observed in other production lines. However, there were high physical and cognitive demands, as the tasks presented different requirements of body postures and efforts; and constant attention and vigilance was required during work.

In spite the aeronautical products present a refined technology embedded in their configuration, factors such as the variety of products, aircraft geometry, low rate of production and the variety of tasks performed required an intensive process of manual work, with intense use of hand and power tools, which was observed.

This embeds into the aircraft assembly work a handmade feature, since the knowledge of the workers to perform the activities is crucial to the quality of the final product.

It may be noted that, regardless the sector where assembly was performed, the process showed critical situations mainly due to: restrictions in the work spaces; uncomfortable and extreme working postures; variability in the work activity generated by the dynamics of the assembling processes; difficulty of communication between workers due to the noisy environment; impact and vibration in the hands and arms generated by activation of pneumatic hammers (power tools); great attention at work, due to the requirement of technical refinement of the assembly process and quality requirements of the final product. 


\subsection{Workers characteristics}

The majority of workers were males $(88.9 \%) ; 52 \%$ were in the age bracket of 21 and 30 years (Table 2). The highest percentage was married or lived with a partner $(64.8 \%)$. Most workers entered working life between 14 and 17 years of age $(55.9 \%)$.

Table 2

Socio-demographic characteristics of workers in aircraft assembly of a Brazilian industry, $2009-2010(n=552)$.

\begin{tabular}{lr}
\hline Variables & $\mathrm{n}(\%)$ \\
\hline Sex & $491(88.9)$ \\
$\quad$ Males & $61(11.1)$ \\
$\quad$ Females & \\
Age & $287(52.0)$ \\
$\quad 21$ to 30 years & $265(48.0)$ \\
$\quad$ Above 30 years & \\
Marital status & $194(35.2)$ \\
$\quad$ Single/divorced/widowed & $358(64.8)$ \\
$\quad$ Married & \\
Education & $229(43.5)$ \\
$\quad$ High school & $277(52.5)$ \\
$\quad$ Technical education & $21(4.0)$ \\
Higher education & \\
Monthly family income & $181(35.9)$ \\
$\quad<$ U\$ 1,580.00 & $197(39.1)$ \\
U\$ 1,581,00 $-2,441.00$ & $126(25.0)$ \\
$\quad>2,441.00$ & \\
Age when entered the labor force & $101(18.8)$ \\
$\quad<14$ years & $300(55.9)$ \\
$14-17$ years & $136(25.3)$ \\
\hline 18 years or more &
\end{tabular}

Table 3 displays some of the occupational features of the studied aircraft assembly workers. The most frequent job title was of mechanical assemblers of aircraft structures $(66.8 \%)$. Almost half of workers were working in the aircraft industry for less than 5 years $(49.5 \%)$.

Regarding time in shiftwork, $54.5 \%$ of workers were in the current shifts less than 5 years; and the majority of the night workers were also less than 5 years working at night. Regarding conflicts in the workplace, almost half of the workers reported that "sometimes" they face work conflicts with superiors and colleagues.

The reports on items related to mental efforts at work called one attention to the question "requiring important concentration to perform the tasks". Almost all respondents indicated this requirement is often/always necessary.
Table 3

Work features of aircraft assembly of a Brazilian industry, 2009 $2010(\mathrm{n}=552)$.

\begin{tabular}{|c|c|}
\hline Variables & $\mathrm{n}(\%)$ \\
\hline \multicolumn{2}{|l|}{ Job title } \\
\hline Mechanical assembler of aeronautical structures & $369(66.8)$ \\
\hline Mechanical assembler of aircrafts & $108(19.6)$ \\
\hline Electrician aircraft assembler & $75(13.6)$ \\
\hline \multicolumn{2}{|l|}{ Time working in the industry } \\
\hline$<5$ years & $273(49.5)$ \\
\hline $5-10$ years & $169(30.6)$ \\
\hline$>10$ years & $110(19.9)$ \\
\hline \multicolumn{2}{|l|}{ Time working at aircraft assembly } \\
\hline$<5$ years & $298(54.0)$ \\
\hline $5-10$ years & $168(30.4)$ \\
\hline$>10$ years & $86(15.6)$ \\
\hline \multicolumn{2}{|l|}{ Time working in the current shift } \\
\hline$<5$ years & $301(54.5)$ \\
\hline $5-10$ years & $184(33.3)$ \\
\hline$>10$ years & $67(12.1)$ \\
\hline \multicolumn{2}{|l|}{ Time as night worker } \\
\hline$<5$ years & $193(85.4)$ \\
\hline $5-10$ years & $27(11.9)$ \\
\hline$>10$ years & $6(2.7)$ \\
\hline \multicolumn{2}{|l|}{ Conflicts with superiors at work } \\
\hline Never & $239(51.3)$ \\
\hline Sometimes & $202(43.3)$ \\
\hline Often/always & $25(5.4)$ \\
\hline \multicolumn{2}{|l|}{ Conflict with colleagues at work } \\
\hline Never & $152(29.5)$ \\
\hline Sometimes & $306(59.4)$ \\
\hline Often/always & $57(11.1)$ \\
\hline \multicolumn{2}{|l|}{ Mental effort at work } \\
\hline \multicolumn{2}{|l|}{ To make quickly decisions } \\
\hline Never/almost never & $87(16.0)$ \\
\hline Sometimes & $216(39.6)$ \\
\hline Often/always & $242(44.4)$ \\
\hline \multicolumn{2}{|l|}{ Important concentration to perform the tasks } \\
\hline Never/almost never & $2(0.4)$ \\
\hline Sometimes & $19 \quad(3.5)$ \\
\hline Often/always & $528(96.2)$ \\
\hline \multicolumn{2}{|l|}{ Using complex procedures at work } \\
\hline Never/almost never & $71(13.1)$ \\
\hline Sometimes & $186(34.2)$ \\
\hline Often/always & $287(52.8)$ \\
\hline \multicolumn{2}{|l|}{ Transmission of accurate information } \\
\hline Never/almost never & $66(12.2)$ \\
\hline Sometimes & $138(25.6)$ \\
\hline Often/always & $335(62.2)$ \\
\hline
\end{tabular}

The characteristics related to habits and lifestyles are presented in Table 4. Most workers reported: did not smoke $(76.9 \%)$, but consumed alcoholic beverages $(65.2 \%)$. Caffeine intake was reported by almost all participants, and a high proportion of caffeine drinkers $(51.9 \%)$ consumed more than 300 milligrams daily.

The regular practice of physical exercise was reported by $56.7 \%$ of workers. The highest proportion of workers had eutrophic body mass index (BMI). On the other hand $37 \%$ of the population was overweight 
or obese; $16.2 \%$ of workers reported problems with insomnia and $22.1 \%$ reported at least one sleep disorder.

Table 4

Smoking and drinking habits and sleep outcomes of workers in aircraft assembly of a Brazilian industry, $2009-2010(\mathrm{n}=552)$.

\begin{tabular}{|c|c|}
\hline Variables & $\mathrm{n}(\%)$ \\
\hline \multicolumn{2}{|l|}{ Smoker } \\
\hline Yes & $45 \quad(8.2)$ \\
\hline No/ex-smoker & $507(91.8)$ \\
\hline \multicolumn{2}{|l|}{ Alcohol consumption } \\
\hline Yes & $360(65.2)$ \\
\hline No & $192(34.8)$ \\
\hline \multicolumn{2}{|c|}{ Amount of alcohol consumed per day } \\
\hline Up to 20 grams/day & $319(88.6)$ \\
\hline More than 20 grams/day & $41(11.4)$ \\
\hline \multicolumn{2}{|l|}{ Caffeine consumption } \\
\hline Yes & $545(98.7)$ \\
\hline No & 7 (1.3) \\
\hline \multicolumn{2}{|c|}{ Amount of caffeine intake per day } \\
\hline Up to $300 \mathrm{mg} / \mathrm{day}$ & $262(48.1)$ \\
\hline More than $300 \mathrm{mg} /$ day & $283(51.9)$ \\
\hline \multicolumn{2}{|c|}{ Regular practice of physical exercise } \\
\hline Yes & $313(56.7)$ \\
\hline No & $239(43.3)$ \\
\hline \multicolumn{2}{|c|}{ Total time of physical exercise per week } \\
\hline $30-140 \mathrm{~min} . /$ week & $93(29.6)$ \\
\hline $150-300 \mathrm{~min} . /$ week & $147(47.0)$ \\
\hline$>300 \mathrm{~min} . /$ week & $73(23.4)$ \\
\hline \multicolumn{2}{|l|}{ BMI } \\
\hline Eutrophic & $348(63.0)$ \\
\hline Overweight/obese & $204(37.0)$ \\
\hline \multicolumn{2}{|l|}{ Insomnia } \\
\hline Yes & $89(16.2)$ \\
\hline No & $459(83.8)$ \\
\hline \multicolumn{2}{|l|}{ Drowsiness } \\
\hline Yes & $243(45.6)$ \\
\hline No & $290(54.4)$ \\
\hline \multicolumn{2}{|l|}{ Sleep problems } \\
\hline Yes & $121(22.1)$ \\
\hline No & $427(78.1)$ \\
\hline
\end{tabular}

\subsection{Musculoskeletal symptoms among aircraft as- sembly workers}

Musculoskeletal symptoms were reported as pain, discomfort and numbness in various body regions.

Table 5 shows the body regions of these symptoms. The most reported regions were: lower back, knees, neck and shoulders, both in the last twelve months and in the last seven days. It is likely the symptoms in these regions were related with higher rates of absence from work.

Table 5

Distribution of musculoskeletal symptoms reported by workers of aircraft assembly sector of a Brazilian industry, $2009-2010$ (n = $552)$.

\begin{tabular}{lrrr}
\hline Body region & $\begin{array}{r}\text { Past 12 months } \\
\text { n (\%) }\end{array}$ & $\begin{array}{r}\text { Past 7 days } \\
\text { n (\%) }\end{array}$ & $\begin{array}{r}\text { Leaves in last } \\
12 \text { months } \\
\text { n (\%) }\end{array}$ \\
\hline Lower back & $164(29.7)$ & $92(16.7)$ & $45(8.2)$ \\
Knees & $161(29.2)$ & $85(15.4)$ & $59(10.7)$ \\
Neck & $163(29.5)$ & $61(11.1)$ & $23(4.2)$ \\
Shoulders & $150(28.7)$ & $76(13.8)$ & $36(6.5)$ \\
Upper back & $122(22.1)$ & $57(10.3)$ & $22(4.0)$ \\
Ankles/feet & $77(13.9)$ & $52(9.4)$ & $29(5.3)$ \\
Wrists/hands & $91(16.5)$ & $47(8.5)$ & $26(4.7)$ \\
Forearms & $64(11.6)$ & $36(6.5)$ & $19(3.4)$ \\
Elbows & $36(6.5)$ & $17(3.1)$ & $12(2.2)$ \\
Hips/Thighs & $43(7.8)$ & $26(4.7)$ & $10(1.8)$ \\
\hline
\end{tabular}

Table 6 presents the body regions most frequently mentioned by workers affected by musculoskeletal symptoms, according to shifts in the assembly of the aircraft industry. Both in past twelve months and past seven days they were: knees, lower back, neck and shoulders for shift 1 and 2 . In shift 3 , symptoms for the upper back were also reported.

Table 6

Distribution of musculoskeletal symptoms per shift reported by workers in aircraft assembly of a Brazilian industry, $2009-2010(\mathrm{n}=552)$.

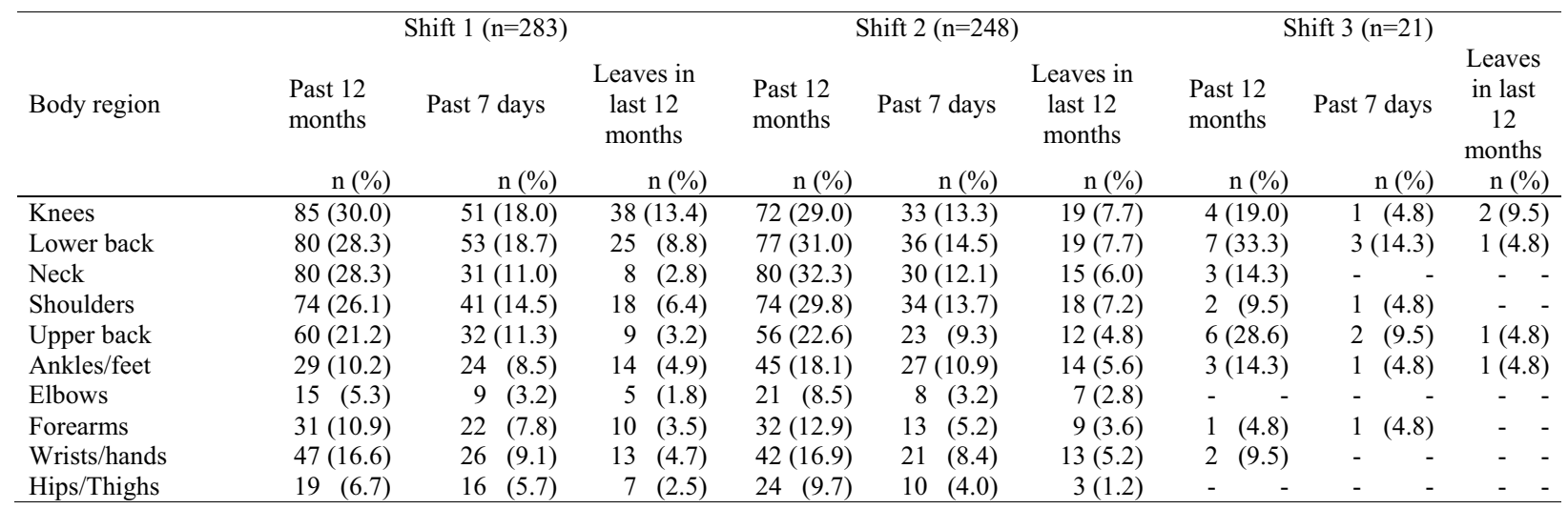


Table 7 presents the final model for the main variables associated with reports of musculoskeletal symptoms for the last twelve months. Conflicts with colleagues at work are positively associated with the reported musculoskeletal symptoms. It can be ob- served a positive association between lack of time for personal care, mental fatigue after work and reporting sleep and sleepiness at work. The practice of regular physical exercise was negatively associated to musculoskeletal reported symptoms.

Table 7

Final model for variables associated with musculoskeletal symptoms in the past twelve months (prior to data collection) among aircraft assembly workers of a Brazilian industry, $2009-2010(\mathrm{n}=380)$.

\begin{tabular}{|c|c|c|c|c|c|}
\hline Factors: variables & $\mathrm{n}(\%)$ & OR crude (IC95\%) & $\mathrm{p}$ & OR adjusted (IC95\%) & $\mathrm{p}$ \\
\hline \multicolumn{6}{|l|}{ Conflicts with colleagues at work } \\
\hline Never & $81(22.6)$ & 1 & & 1 & \\
\hline Sometimes/frequently/always & $278(77.4)$ & $2.86(1.92 ; 4.28)$ & 0.0001 & $2.69(1.67 ; 4.35)$ & 0.0001 \\
\hline \multicolumn{6}{|l|}{ Lack of time for personal care } \\
\hline No & $94(26.8)$ & 1 & & 1 & \\
\hline Yes & $257(73.2)$ & $3.03(2.04 ; 4.50)$ & 0.0001 & $2.07(1.29 ; 3.32)$ & 0.002 \\
\hline \multicolumn{6}{|c|}{ Perceived mental fatigue at the end of work shift } \\
\hline Never/sometimes & $254(66.8)$ & 1 & & 1 & \\
\hline Frequently/always & $126(33.2)$ & $3.74(2.24 ; 6.25)$ & 0.0001 & $2.26(1.23 ; 4.14)$ & 0.008 \\
\hline \multicolumn{6}{|l|}{ Sleep disorders } \\
\hline No & $278(73.9)$ & 1 & & 1 & \\
\hline Yes & $98(26.1)$ & $2.40(1.45 ; 3.97)$ & 0.0001 & $2.17(1.17 ; 4.03)$ & 0.01 \\
\hline \multicolumn{6}{|c|}{ Regular practice of sports/exercise off-work } \\
\hline No & $255(67.1)$ & 1 & & 1 & \\
\hline Yes & $125(32.9)$ & $0.55(0.38 ; 0.79)$ & 0.001 & $0.61(0.38 ; 0.96)$ & 0.03 \\
\hline \multicolumn{6}{|l|}{ Feeling sleepy at work } \\
\hline Never & $143(39.3)$ & 1 & & 1 & \\
\hline Sometimes/frequently/always & $221(60.7)$ & $2.24(1.54 ; 3.24)$ & 0.0001 & $1.58(1.01 ; 2.52)$ & 0.05 \\
\hline
\end{tabular}

Table 8 shows the final model of the main factors independently associated with reported musculoskeletal symptoms for the past seven days. As surprising as it can be, time working as operator at the aircraft assembly was not significant associated. However, the work organization, particularly shiftwork sche- dules, that can be directly associated with lack of time to adequate rest during the working week, fatigue, sleepiness during work, and sleep disturbances, showed significance. Also, a psychosocial factor at work (conflicts with superiors) was relevant.

Table 8

Final model for variables associated with musculoskeletal symptoms in the last seven days (prior to data collection) among workers in aircraft assembly of a Brazilian industry, $2009-2010(n=235)$.

\begin{tabular}{|c|c|c|c|c|c|}
\hline Factors: variables & $\mathrm{n}(\%)$ & OR crude (IC95\%) & $\mathrm{p}$ & OR adjusted (IC95\%) & $\mathrm{p}$ \\
\hline \multicolumn{6}{|l|}{ Lack of time for personal care } \\
\hline No & $53(24.5)$ & 1 & & 1 & \\
\hline Yes & $163(75.5)$ & $2,50(1.69 ; 3.68)$ & 0.0001 & $2,53(1.56 ; 4.09)$ & 0.0001 \\
\hline \multicolumn{6}{|l|}{ Feeling sleepy at work } \\
\hline Never & $81(36.3)$ & 1 & & 1 & \\
\hline Sometimes/frequently/always & $142(63.7)$ & $1.91(1.34 ; 2.72)$ & 0.0001 & $1.99(1.25 ; 3.15)$ & 0.003 \\
\hline \multicolumn{6}{|l|}{ Time working in the industry } \\
\hline Up to 5 years & $118(50.4)$ & 1 & & 1 & \\
\hline More than 5 years & $116(49.6)$ & $1.85(1.31 ; 2.62)$ & 0.0001 & $2,66(1.12 ; 6.34)$ & 0.02 \\
\hline \multicolumn{6}{|l|}{ Sleep problem during the week } \\
\hline No & $173(77.2)$ & 1 & & 1 & \\
\hline Yes & $51(22.8)$ & $3.29(1.96 ; 5.50)$ & 0.0001 & $1.87(1.00 ; 3.49)$ & 0.05 \\
\hline \multicolumn{6}{|l|}{ Conflicts with superiors at work } \\
\hline No & $81(41.8)$ & 1 & & 1 & \\
\hline Yes & $113(58.2)$ & $1.93(1.33 ; 2.80)$ & 0.001 & $1.56(1.00 ; 2.44)$ & 0.05 \\
\hline
\end{tabular}




\section{Discussion}

This study aimed to evaluate variables associated with reported musculoskeletal symptoms among workers of aircraft assembly. The body regions with the highest prevalence of reported musculoskeletal symptoms were similar when referred the past twelve months and the past seven days.

The results of this study are similar to those found in previous study [19] evaluating aircraft assembly workers. Other studies investigating the prevalence of musculoskeletal disorders among workers in assembly lines found similar results to those reported in the present study.

Due to the intensive use of power hand tools it was expected a significant prevalence of musculoskeletal symptoms in the region of the wrist and hands. However, these results were not confirmed. Perhaps this lower prevalence observed in comparison to other body regions is due to the company's initiatives seeking to reduce vibration of hand tools, promoting the use of devices such as specific anti-vibration gloves and grip covers in the hand tools. As was reported previously [10] workers who make intensive use of pneumatic hammers require appropriate control to protect against the risk of developing musculoskeletal disorders related to vibration.

Another study evaluating the influence of the use of devices to reduce the vibration of jackhammers, used by workers in aircraft assembly [4], found that the use of these devices may decrease by up to $70 \%$ transmission of vibration of the hammer to the upper limb of the worker.

A significant postural demand in the aircraft assembly was observed. However, the multivariate analysis did not show significant association of posture and musculoskeletal symptoms, although these variables adjusted the final models. Previous studies $[6,15]$ showed the association of the adoption of awkward postures at work and the report of musculoskeletal symptoms, especially the lower back. In these studies, it appears that the duration of a particular posture is more important for the occurrence of complaints than its frequency because it can influence the workers' perception on demands and difficulties related to the performance of work tasks.

Sleepiness at work and the pre-existence of sleep disorders were associated to reporting of musculoskeletal symptoms. The role of these variables on the musculoskeletal symptoms may be related to fatigue and shift work. Previous studies $[1,3,7,8]$ looking at different work contexts have shown that shift workers are prone to the development of sleep disturbances and sleepiness at work, which negatively influences the quality of the recovery after working hours. This can trigger other health outcomes, including fatigue.

This argument is reinforced when one observes that the mental fatigue at the end of work shift, lack of time for personal care and lack of time to rest during the week were associated with the musculoskeletal symptoms in the last 12 months and the last seven days.

The association between conflicts at work and musculoskeletal symptoms has been described in previous studies $[14,18]$ and is related to the roles played by each group (employers, managers and workers) in the workplace. It is interesting to note that conflicts with co-workers are associated to reported musculoskeletal symptoms in the medium/long term (past twelve months), adding a chronic component.

On the other hand, the conflicts with superiors were associated with the perception of acute symptoms in the past week ( 7 days). This might be due to the fact that workers spend more time with their coworkers than with their superiors, although there are conflicts in both cases.

The influence of time on the job on the development of musculoskeletal symptoms or musculoskeletal disorders has been reported in previous publications [9]. In the present study, time in company was associated with reported musculoskeletal symptoms in the past seven days. It was expected this association would also occurred in the past 12 months, but this could not be confirmed in the present study.

The practice of regular physical activity or sports during off-working time was a positive factor in preventing musculoskeletal symptoms. Perhaps this is due to the benefits attributed to regular exercise, including the improvement in overall physical fitness of individuals $[2,5]$.

\section{Study limitations}

The cross-sectional design used in this study does not allow the establishment of causal relations, since both exposure to risk factors and their effects were evaluated simultaneously. However these analyses showed it is necessary to routinely perform evaluations of the work activities and health symptoms in order to prevent chronic problems and further work disability. 


\section{Conclusions}

The analysis of factors associated with reported musculoskeletal symptoms among workers of aircraft assembly, highlights the multifactorial nature of the problem. Characteristics related to their health as well as organizational aspects of the work interact to produce significant effects on workers.

Actions to prevent musculoskeletal diseases at the aircraft assembly work should consider multiple interventions, including the organizational aspects of work. It is also required the implementation of adequate working time schedules that would promote better recovery between work shifts.

\section{Acknowledgments}

Fabrício Augusto Menegon received a doctoral scholarship from the Brazilian Research Agency (CNPq) during his graduate program at the School of Public Health, University of São Paulo, Brazil; he also received financial support from the Federal University of Itajubá (UNIFEI), Brazil, to participate in IEA 2012. He was supervised by Frida Marina Fischer who is a recipient of CNPq (Productivity Grant, category $1 \mathrm{~B})$. We also thank the aircraft industry to their support and the workers who participated in this study.

\section{References}

[1] E. Ahsberg, G. Kecklund, T. Åkerstedt and F. Gamberale, Shiftwork and different dimensions of fatigue, International Journal of Industrial Ergonomics 26 (2000), 457-465.

[2] M.C. Battie, S.J. Bigos, L.D. Fisher, T.H. Hansson, A.L. Nachemson, D.M. Spengler, M.D. Wortley and J. Zeh, A prospective study of the role of cardiovascular risk factors and fitness in industrial back pain complaints, Spine, 14 (1989), 141-147.

[3] S.D. Baulk, A. Fletcher, K,J, Kandelaars, D. Dawson, and G.D. Roach, A field study of sleep and fatigue in a regular rotating 12-h shift system, Applied Ergonomics 40 (2009), 694-698.

[4] P.E. Boileau, J. Boutin, P. Drovin and H. Scory, Les vibrations engendrées par les marteaux-riveteurs dans l'assemblage aérospatial, Études et Recherche, IRSST, Rapport (1994), $54 \mathrm{p}$

[5] B.R. Costa and E.R. Vieira, Stretching to reduce workrelated musculoskeletal disorders: a systematic review, Journal of Rehabilitation Medicine 40 (2008), 321328.

[6] J. Duquette, M. Lortie and M. Rossignol, Perception of difficulties for the back related to assembly work: gen- eral findings and impact of back health, Applied Ergonomics, 28 (1997), 389-396.

[7] F.M. Fischer, F.N.S. Borges, L. Rotenberg, M.R..D.O. Latorre, N.S. Soares, P.L.F.S. Rosa, L.R. Teixeira, R. Nagai, J. Steluti and P. Landsbergis, Work ability of health care shift workers: what matters?, Chronobiology International, 23 (2006), 1165-1179.

[8] G.H. Halvani, M. Zare and S.J. Mirmohammadi, The relation between shift work, sleepiness, fatigue and accidents in Iranian Industrial Mining Group workers, Industrial Health, 47 (2009), 134-138.

[9] A. Kaergaard and J.H. Andersen, Musculoskeletal disorders of the neck and shoulders in female sewing machine operators: prevalence, incidence, and prognosis, Occupational and Environmental Medicine, 57 (2000), 528-534.

[10] B. Kattel and J.E. Fernandez, The effects of rivet guns on hand-arm vibration, International Journal of Industrial Ergonomics, 23 (1999), 595-608.

[11] I. Kuorinka, B. Jonsson, A. Kilbom, H. Vinterberg, F. Biering-Sorensen and G. Andersson, Standardised Nordic questionnaires for the analysis of musculoskeletal symptoms, Applied Ergonomics 18 (1987), 233-237.

[12] J.M. Melhorn, L. Wilkinson and J.D. Riggs, Management of musculoskeletal pain in the workplace, Journal of Occupational and Environmental Medicine 43 (2001), 83-93.

[13] F.A. Pinheiro, B.T. Tróccoli and C.V.D. Carvalho, Validação do Questionário Nórdico de Sintomas Ósteomusculares como medida de morbidade, Journal of Public Health 36 (2002), 307-312.

[14] A. Pisarski, S.A. Lawrence, P. Bohle and C. Brook, Organizational influences on the work life conflict and health of shiftworkers, Applied Ergonomics 39 (2008), 580-588.

[15] V. Putz-Anderson, B. Bernard, S. Burt, L. Cole, C. Fairfield-Estill, L. Fine, K. Grant, Musculoskeletal disorders and workplace factors: a critical review of epidemiologic evidence for work-related musculoskeletal disorders of the neck, upper extremity and low back. Public Health 1, NIOSH - National Institute for Occupational Safety and Health, (1997).

[16] V.N. Rajan, K. Sivasubramanian and J.E. Fernandez, Accessibility and ergonomic analysis of assembly product and jig designs, International Journal of Industrial Ergonomics 23 (1999), 473-487.

[17] P.A. Ramadan and M. Ferreira, Risk factors associated with the reporting of musculoskeletal symptoms in workers at a laboratory of clinical pathology, The Annals of Occupational Hygiene 50 (2006), 297-303.

[18] L.E. Rocha, D.M.R. Glina, M.F. Marinho and D. Nakasato, Risk factors for musculoskeletal symptoms among call center operators of a bank in São Paulo, Brazil, Industrial Health 43 (2005), 637-46.

[19] V.M.S. Secchin, Implicações da organização da produção e do trabalho na atividade dos montadores de montagem estrutural, Master Degree Dissertation, Federal University of São Carlos, 2007. 